\title{
Ozonation in Tandem with Biosand Filtration to Remove Microcystin-LR
}

\author{
Pratik Kumar $^{1}$; Satinder Kaur Brar, Ph.D. ${ }^{2}$; and Rao Y. Surampalli, Ph.D., Dist.M.ASCE ${ }^{3}$
}

\begin{abstract}
A hybrid ozonation-biofiltration approach is evaluated to understand the necessity and concentration of ozone dose in removing the micropollutant microcystin-LR (MC-LR). To simulate real polluted water, three levels of natural organic matter-1, 2, and $5 \mathrm{mg} / \mathrm{L}-\mathrm{and}$ cyanobloom intensity—low, medium, and high—under ozone exposure times—C1: $0.8 \mathrm{mg} \times \mathrm{min} / \mathrm{L}$ and $\mathrm{C} 2: 1.6 \mathrm{mg} \times \mathrm{min} / \mathrm{L}-$ were studied (18 combinations in total). The feasibility of filter bioaugmentation (postozone treatment) using known MC-LR degraders Arthrobacter ramosus (Filter FA) and Bacillus sp. (Filter FB) is also discussed and compared with the feasibility of a noninoculated sand filter. Overall, the bioaugmented sand filters, FA and FB, enhanced filter performance by $19.5 \%$ and $10.5 \%$ for $\mathrm{Cl}$ samples and $6 \%$ and $2 \%$ for C2 samples, respectively, in terms of MC-LR removal. All three filters, including the control (FC), showed a negative correlation (FA: -0.987; FB: -0.973; FC: -0.977) between "residual ozone" and "MC-LR removal due to ozonation." However, A. ramosus (Filter FA) showed strong resilience toward the residual ozone $(0.1-0.4 \mathrm{mg} / \mathrm{L})$ and did not affect MC-LR removal due to filtration as much as it affected Filters FB and FC. Only Filter FA showed a significant difference ( $p$-value: 0.047) between bloom condition and MC-LR removal that showed less removal of the latter at higher bloom intensity and vice versa. Statistical analysis, too, suggested a strong influence of natural organic matter (NOM) on filter performance for MC-LR removal. Also, protein phosphatase inhibition assay (PPIA) toxicity showed less toxic by-product formation when native bacteria were co-cultured and inoculated with A. ramosus and Bacillus sp.) in a sand filter. Hence, combined ozonation-biofilter treatment using co-inoculation may simplify (eco)toxicological and biotransformation research. This will enable the study of diverse contaminants under other environmental parameters. DOI: 10.1061/(ASCE)EE.1943-7870.0001801. () 2020 American Society of Civil Engineers.
\end{abstract}

Author keywords: Biofilter; Microcystin; Case study; Techno-economic analysis; Ozonation; Emerging contaminant.

\section{Introduction}

1 Drinking water sources, such as lakes, rivers, and ponds, are increasingly affected by the presence of emerging contaminants even at a very low concentrations (1-100 $\mu \mathrm{g} / \mathrm{L}$ ) (Petrovic et al. 2004). In general, drinking water treatment plants (DWTPs) do not completely remove these contaminants where conventional treatment units or processes are found to be less effective (Petrovic et al. 2003). The co-occurrence of macropollutants in the form of metal ions, natural organic matter, and recalcitrant substances renders partial removal of these emerging contaminants. This necessitates a choice of high input dosage of oxidants (chlorine and ozone) during the pretreatment steps. These chemical oxidants have been widely applied in water treatment for over a century, primarily for disinfection and later for the abatement of inorganic and organic contaminants. The main challenges involve the formation of toxic by-products and other (eco)toxicological consequences (von Gunten 2018). Pretreatment in a DWTP, such as prechlorination and

${ }^{1} \mathrm{Ph} . \mathrm{D}$. Candidate, Institut national de la recherche scientifique- Eau, Terre and Environment, Université du Québec, QC, Canada G1K 9A9. Email: pratik.kumar@ete.inrs.ca

${ }^{2}$ Professor, Dept. of Civil Engineering, Lassonde School of Engineering, York Univ., North York, Toronto, ON, Canada M3J 1P3 (corresponding author). Email: satinder.brar@lassonde.yorku.ca; satinder.brar@ ete.inrs.ca

${ }^{3}$ Professor, Dept. of Civil Engineering, Univ. of Nebraska-Lincoln, Lincoln, NE 68588-6105. Email: surampallirao@gmail.com

Note. This manuscript was submitted on January 6, 2020; approved on June 9, 2020No Epub Date. Discussion period open until 0, 0; separate discussions must be submitted for individual papers. This paper is part of the Journal of Environmental Engineering, (C) ASCE, ISSN 0733-9372. preozonation, is very common, especially the former. However, various health risk factors or issues have been reported so far due to prechlorination practice (Brown 2016). Moreover, the presence of residual chlorine triggers the formation of disinfection by-products, such as trihalomethanes and brominated compounds (Li and Mitch 2018). On the other hand, in a preozonation treatment unit, a lower oxidant (ozone) dose $(<3 \mathrm{mg} / \mathrm{L})$ and a shorter exposure time ( $<4$ min compared with $>25$ min for chlorination) make it a more rapid and effective option than the latter. Preozonation plays an important role in breaking down recalcitrant and complex organic matter, which is subsequently removed by the coagulation and filtration unit (Cui et al. 2014; Zoumpouli et al. 2019).

The ozone dose used in a DWTP may not be enough for complete removal of both macro- and micropollutants, especially when preozonation is practiced before sedimentation and filtration. An enhanced dose is required if a complex matrix is encountered, such as natural organic matter (NOM), cyanobacterial bloom, and other organic compounds (Goel et al. 1995; De Vera et al. 2015). However, various questions arise: (1) What is the optimum dose? (2) What are the ecotoxicological consequences of toxic byproducts generated from ozonation; and (3) Efficiency of the successive treatment units, such as filtration, in tackling by-products formation. Some researchers have studied and highlighted the importance of inoculated filters (biofilters) which have been shown to enhance the removal of unconventional and recalcitrant pollutants such as N,N-diethyl-meta-toluamide (DEET), naproxen, and ibuprofen (Hallé et al. 2015). Some pollutants are even recalcitrant to further degradation and may include their by-products as well (Schlüter-Vorberg et al. 2015). Ozonation is usually combined with biofiltration steps such as sand filtration to remove biodegradable organic carbon and break down transformed by-products 
(Gerrity et al. 2018). Zoumpouli et al. (2019) studied the ozonationbiofilter combination of water treatment for five trace organic contaminants: acesulfame, carbamazepine, diclofenac, dimethylsulfamide, and fluoxetine. The complex transformed by-products from ozonation such as N-nitrosodimethylamine (NDMA) and an acesulfame product were removed from the biofilter while the recalcitrant oxidation products such as trifluoroacetic acid (TFA) and two products from diclofenac were removed partially. Thus, the combination of ozonation and a biofilter is potentially effective at degrading cyanotoxins.

However, bioactivity in the filters can be inhibited by influent laden with the toxic by-products resulting from the use of a higher than normal ozone dose. Hence, the residual ozone from the ozonation unit may affect biofilter operation. For this reason, residual ozone is hypothesized to be an important parameter, as an excess oxidant level may stress and kill the inoculated microorganism during biofilter operation which can subsequently lower the removal efficiency of micropollutants and other organic matter. However, the ozone half-life in pure water can range anywhere from 20 to $60 \mathrm{~min}$, depending on $\mathrm{pH}$, temperature, and other environmental factors (Gardoni et al. 2012). These factors must be considered when studying the effect of residual ozone on a biofilter.

In the present study, three levels of $\operatorname{NOM}(1,2$, and $5 \mathrm{mg} / \mathrm{L})$ and algal bloom intensity (low, medium, and high) were studied along with a model micropollutant (emerging contaminants) in the form of microcystin-LR (MC-LR). MC-LR is a very common algal toxin present in drinking water sources. Two dose exposure times were also studied $(0.8$ and $1.6 \mathrm{mg} \times \mathrm{min} / \mathrm{L})$ for the ozonation experiment. In addition, two biosand filters inoculated individually with MC-LR degraders $A$. ramosus and Bacillus sp. were operated in tandem with ozone treatment. Many DWTPs have a filtration unit in succession to a preoxidation treatment unit (prechlorination or preozonation) where sand is used as a common (or conventional) adsorbing medium. Hence, a hybrid operation of ozonation and filtration was evaluated to understand the level of ozone treatment (in terms of exposure time at a given ozone dose) required for maximum MC-LR removal from the polluted source water. The toxicity of the filtered water was further checked by PPIA to determine the significance of co-culturing in a biosand filter for MC-LR removal (biodegradation). To the best of the authors' knowledge, this is the first study to focus on MC-LR removal based on the residual ozone hypothesis, where the performance of ozonation and the biofilter is evaluated in tandem.

\section{Materials and Methods}

\section{Chemicals and Reagents}

MC-LR was purchased from Cayman Chemicals (Ann Arbor, Michigan), and a stock solution of $50 \mathrm{mg} / \mathrm{L}$ was made by diluting $100 \mu \mathrm{g}$ lyophilized MC-LR film (as supplied) using $2 \mathrm{~mL}$ methanol and was stored at $-20^{\circ} \mathrm{C}$. Crystal violet and 3-(4, 5-dimethylthiazol2-yl)-2,5-diphenyltetrazolium bromide (MTT) were purchased from Sigma Aldrich (Ontario, Canada). Quartz sand was obtained from the Chemin Ste-Foy DWTP (Quebec City, Canada). For the PPIA, the enzyme and substrate - respectively protein phosphatase-1 catalytic subunit ( $\alpha$-isoform from rabbit) and p-nitrophenyl phosphate (pNPP)—were purchased from Sigma Aldrich.

The MC degraders A. ramosus [Northern Regional Research Laboratory (NRRL) B-3159] and Bacillus sp. (NRRL B-14393) were purchased from the NRRL Agricultural Research Service (ARS, Washington, District of Columbia) culture collection. All analytical reagents used in preparing nutrient and culture media, liquid chromatography-mass spectra (LC-MS)-grade solvents, and reagents used to prepare analytical mobile phases were purchased from Fisher Scientific (Ontario, Canada).

\section{Culture and Growth of Microcystis Aeruginosa}

A 5-mL culture of M. Aeruginosa, kindly provided by Dr. Jerome Compte, assistant professor, INRS-ETE, Quebec City, Canada), was subcultured multiple times in BG-11 medium as discussed in Khong et al. (2019) to obtain 2.5 L of culture stock. A relationship between optical density (OD) at $\lambda_{700 \mathrm{~nm}}$ and cell concentration was found. The cell count was performed using a hemocytometer after brief sonication of the culture to release any colony attachment in suspension.

\section{Sample Preparation for Ozone Treatment}

The variables studied were ozone dose exposure time (two levels), cyanobloom intensity (three levels), and NOM (three levels), for a total of 18 variable combinations. Water from Lake Sainte-Anne $(47.262879 \mathrm{~N},-71.665158 \mathrm{~W})$ was used as the matrix for sample preparation. Around $50 \mathrm{~mL}$ was prepared (more than one-bed volume for the filter) for all 18 combinations in 125-mL Erlenmeyer flasks. Ozone was produced by a module Ozonair EMO3-131 (EMO3, Quebec City, Canada), with a flow of $47.195 \mathrm{~L} / \mathrm{s}$ and a minimum rate of conversion of $0.02 \mathrm{ppm}$.

Humic acid was used as the representative chemical to mimic $\mathrm{NOM}$ at $1 \mathrm{mg} / \mathrm{L}(\mathrm{N} 1), 2 \mathrm{mg} / \mathrm{L}(\mathrm{N} 2)$, and $5 \mathrm{mg} / \mathrm{L}(\mathrm{N} 3)$. At the Chemin Ste-Foy DWTP, the normal ozone input dose varies in the range $0.6-1.0 \mathrm{mg} / \mathrm{L}$ for a retention time of $2-3 \mathrm{~min}$. However, concentration $\times$ time for the ozone dose in the present study was $1.2-3 \mathrm{mg} \times \mathrm{min} / \mathrm{L}$ because an analysis of the effect of ozone as a by-product on biofilter performance required a lower range. Therefore, low $(\mathrm{C} 1: 0.8 \mathrm{mg} \times \mathrm{min} / \mathrm{L})$ and high $(\mathrm{C} 2: 1.6 \mathrm{mg} \times \mathrm{min} / \mathrm{L})$ ozone dose contact times (CT; equals concentration $\times$ time $)$ were tested.

\section{Bloom Intensity and M. Aeruginosa Relationship}

Three bloom intensity OD values were considered $\left(\lambda_{\max }=\right.$ $700 \mathrm{~nm}$ ): 0.2 (B1: low), 0.5 (B2: medium), and 1.0 (B3: high) corresponding to $1.9 \times 10^{6}, 4.3 \times 10^{6}$, and $8.4 \times 10^{6}$ cells $/ \mathrm{mL}$, respectively. The $M$. aeruginosa culture used to mimic the bloom was also tested for any production of cyanotoxin. In all, 12 toxins were checked and none were found at any stage of growth. Hence, to simulate cyanotoxin, commercial MC-LR was externally added to provide an initial concentration of $50 \mu \mathrm{g} / \mathrm{L}$ in each sample.

\section{Culture and Biofilm Formation of MC-LR Degraders over Sand Filters}

Two MC-LR degraders, A. ramosus and Bacillus sp., were tested individually for bioaugmentation in the sand filter (Filter FA and Filter FB, respectively). Both were cultured and rinsed with a phosphate buffer $(\mathrm{pH}=7.21)$ to obtain cell pellets with $\mathrm{OD}_{600}$ values of 0.7 and 0.9 , representing $3 \times 10^{6}$ cells $/ \mathrm{mL}$ for $A$. ramosus and Bacillus sp., respectively. According to the relationship between $\mathrm{OD}_{600}$ and cell viability (cells $/ \mathrm{mL}$ ), the sand filter was inoculated with $3 \times 10^{6}$ cells $/ \mathrm{mL}$ every $3 \mathrm{~h}$ using an auto-dosage pump for a period of 11 days to initiate fast biofilm formation (more detail is provided in the section "Experimental Setup and Filter Operation"). Lake water was used as the matrix.

Biofilm formation was monitored through three parameters: cell viability, cell biomass, and protein concentration. Around $0.2 \mathrm{~g}$ of sand were collected from the top layer of the sand column and suspended in phosphate buffer $(2.0 \mathrm{~mL})$. The mixture was given a short spin to loosen the attached bacterial cells and 


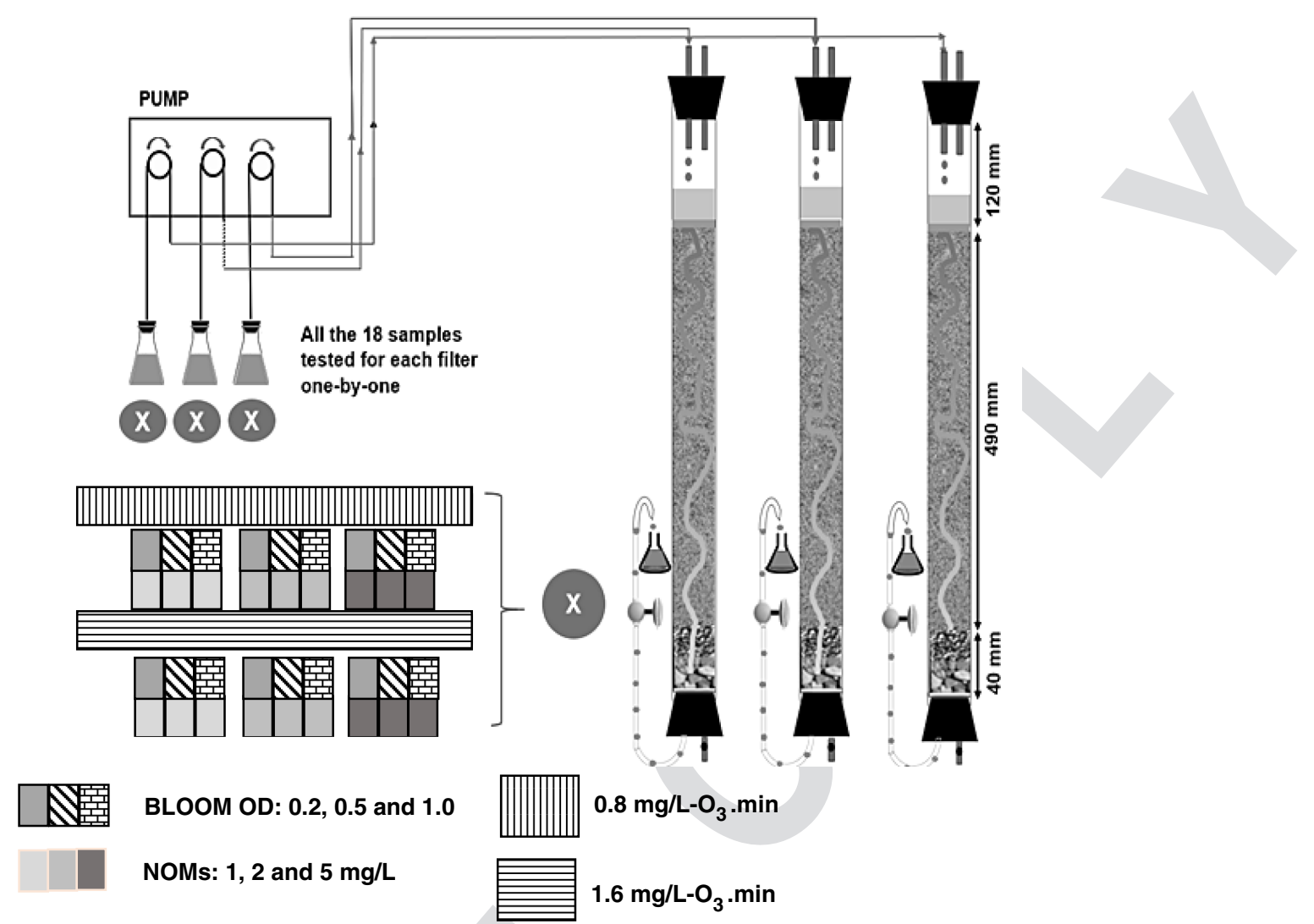

Fig. 1. Schematic of filter operation for the ozone-treated samples.

189 biomass in suspension. The obtained cell suspension was seeded in 190 a 96-well plate for crystal violet (CV) and MTT assay as described 191 in Kumar et al. (2019) to estimate cell biomass and cell viability, 192 respectively. For protein determination, the cell suspension was an193 alyzed using the Bradford assay (Bradford et al. 1976).

\section{Experimental Setup and Filter Operation}

Fig. 1 is a schematic of the three filters (FA, FB, and FC) used in the study. Two were bioaugmented with A. ramosus (FA) and Bacillus sp. (FB) for biofilm formation, and the remaining one served as the control (FC), representing a DWTP filter in which no MC-LR degrader was inoculated. FA and FB were compared with FC to understand the need and importance of sand filter bioaugmentation. All three filters were made up of a glass of 22-mm external diameter, and 1-mm thickness, and 650-mm height $(490 \mathrm{~mm}$ for the sand, $40 \mathrm{~mm}$ for the drainage material, and $120 \mathrm{~mm}$ for standing water/sample headspace). The sand was formulated based on previously reported work (Kumar et al. 2019). The effective diameter of the sand particles was $0.22 \mathrm{~mm}$, and the coefficient of uniformity was 2.3 .

After mature biofilm formation (more details in "Results and Discussion" section), the ozone-treated samples (18 combinations; 9 for each CT) were discharged through each filter postozonation. After the passage of every sample (with the low-intensity bloom samples first), the filters were primed with lake water to minimize the carryover effect of the previous sample. After every three combinations were sampled (in triplicate) - that is, after filtration - the sand was washed, dried, and prepared for fresh filter operation to further minimize error due to the effect of the earlier samples.

\section{MC-LR Analysis and Residual Ozone Determination}

The MC-LR was analyzed at two instances for each sample: once after the ozonation and another after the samples were passed through the sand filter. The undegraded or residual MC-LR was then calculated using Eq. (1) as follows:

$$
\frac{\text { Initial MC }-\mathrm{LR} \text { concentration }(50 \mu \mathrm{g} / \mathrm{L})-\{(\mathrm{MC}-\text { LRremovedafterozonation })-(\mathrm{MC}-\mathrm{LR} \text { removed after filtration })\}}{\text { Initial MC }- \text { LR concentration }(50 \mu \mathrm{g} / \mathrm{L})} \times 100 \%
$$

The protocol used for MC-LR analysis followed Fayad et al. (2015). Briefly, a 20- $\mu \mathrm{L}$ sample aliquot was analyzed by ultrahigh-performance liquid chromatography coupled with mass spectrometry (MS) through a positive electrospray ionization source. In full-scan MS mode (resolution 70,000 FWHM at $200 \mathrm{~m} / \mathrm{z}$ ), MC-LR was detected and quantified against a matrix-matched lake water calibration curve. The limit of quantification (LOQ) was set at the lowest concentration level of the calibration curve (i.e., $1 \mu \mathrm{g} / \mathrm{L}$ ).

The residual ozone concentration in a treated sample was determined by the Indigo method as discussed in Bader and Hoigné (1981). In brief, 1-mM (0.62-g) stock solution of Indigo reagent 
was mixed with 20-mM phosphoric acid (1-L). After each sample was treated with ozone at a given dose $\left(0.8 \mathrm{mg} / \mathrm{L} \mathrm{O}_{3}\right)$ and contact time (1 $\mathrm{min}$ for $0.8-\mathrm{mg} / \mathrm{L} \mathrm{O}_{3} \cdot \mathrm{min} ; 2 \mathrm{~min}$ for $1.6-\mathrm{mg} / \mathrm{L} \mathrm{O}_{3} \cdot \mathrm{min}$ ), the indigo solution was spiked continuously using burette $(0.1-\mathrm{mL}$ least graduation) until the Indigo became colorless or a bit yellowish. This change in color indicated a complete quenching of the residual ozone in the sample.

The experiment for determination of residual ozone was carried out in two matrices: (1) tap water; and (2) a combination of medium bloom intensity (B2: $\mathrm{OD}_{700}$ of 0.5 ) and medium NOM concentration (N2: $2 \mathrm{mg} / \mathrm{L})$. Tap water was used because of the possible high reporting of residual ozone if deionized water were used) and to reduce overestimation and positive error in interpretation of the results. The idea was not to overestimate the residual ozone concentration in the real matrix (bloom + NOM cases) when compared with the tap water (clear), where the former would be expected to consume part of the dissolved ozone because of NOM and cyanobacterial cell inclusion. Also, since the color of the real matrix was a light brownish-green and to make the distinction clear between it and the colorless indigo, the matrix was bypassed using a glass fiber filter (pore size: $0.45 \mu \mathrm{m}$ ). Then the residual ozone concentration was determined as discussed earlier. The effect of the glass fiber filter adsorbing the residual ozone was normalized by filtering the tap water sample while preparing the calibration curve.

A relationship between different contact times and the amount of Indigo solution (to quench the ozone) was established. This relationship was determined for both matrices. The residual ozone concentration in the postozone treatment samples was determined using a visual testing kit that measures ozone in the range $0-2 \mathrm{mg} / \mathrm{L}$ (color coding for ozone concentration: $0.1,0.2,0.3,0.4,0.8,1.0,1.25$, 1.50 , and 2.00). Once the calibration curve was established, the Indigo solution was used for the determination of residual ozone concentration to avoid having to use the expensive kit.

\section{Sample Toxicity Assessment before and after Biofiltration}

The PPIA has been widely used to study the toxic effect of residual MC-LR in water. Protein phosphatase (PP) belongs to the protein serine/threonine phosphatase class and is responsible for control of glycogen metabolism. MC-LR, a hepatotoxin, attacks liver cells and inhibits kinetic PP activity (hence "PPI"). Thus, PPIA is very significant and is specific to MC-LR toxicity.

The assay was performed in a 96-well plate in which the first two rows and columns were not used because of a reported wall effect and temperature differences in them. To initiate the colorimetric reaction, A $300-\mu \mathrm{L}$ solution was produced that consisted of $20-\mu \mathrm{L}$ MC-LR for different concentrations (diluted in reaction buffer), $40-\mu \mathrm{L}$ PP (stock solution diluted in enzyme buffer according to manufacturer specifications; final well concentration: $0.8 \mathrm{U} / \mathrm{mL}$ ), $240-\mu \mathrm{L}$ pNPP (substrate: final well concentration: $120 \mathrm{mM}$ ). A blank without MC-LR was prepared along with the standard concentrations (substrate blank) to represent PPI baseline activity normalized for each well exposed to it to determine how it was affected by MC-LR. The activity rate (hydrolysis of pNPP based on color change) was determined and calculated based on colorimetric absorbance optical density (OD at $\lambda_{\max }: 405 \mathrm{~nm}$; $32^{\circ} \mathrm{C} \pm 3^{\circ} \mathrm{C}$ ) using a Biotek mini spectrophotometer (Winooski, Vermont) every $2 \mathrm{~min}$ for $1 \mathrm{~h}$. A linear rate (change in $\mathrm{OD} / \mathrm{min}$ ) of 1,020-3,520 s was obtained showing that the substrate blank rate plateaued after $1,020 \mathrm{~s}$. The greater the hydrolysis of pNPP substrate by the PP enzyme, the lower the OD value and hence the lower the reported PPI and vice versa. Thus, the higher percentage activity reported, the lower the PPI by MC-LR. For analysis of the water samples, a $20-\mu \mathrm{L}$ sample in place of MC-LR was mixed in wells along with the PPI enzyme and the pNPP substrate as reported previously, and PPI activity was compared with the toxicity change due to residual MC-LR in the sample before and after filtration. All samples were run in triplicates.

An ozone-treated (CT: $0.8 \mathrm{mg} \times \mathrm{min} / \mathrm{L}) 500-\mathrm{mL}$ sample spiked at an initial MC-LR concentration of $50 \mu \mathrm{g} / \mathrm{L}$ was prepared as an influent to the filters for this particular experiment. Filters FA, $\mathrm{FB}$, and FC were primed using ozone-treated water $(40-\mathrm{mL}$ bed volume), and the effluent was measured for percentage PPI activity to determine the toxicity level in the residual MC-LR. The result was also compared with an another ongoing project where coculturing of A. ramosus or Bacillus sp. and native bacteria.

\section{Statistical Analysis and Graphics}

All statistical analyses comprising standard deviation, average, student $t$-test, $p$-value comparison, principal component analysis (PCA), and all graphics were performed in ORIGIN version 8.5 software.

\section{Results and Discussion}

\section{Monitoring Biofilm Growth in the Filter}

Biofilm monitoring was performed for 11 days. Figs. 2(a-d) show the monitoring of protein concentration, crystal violet $(\mathrm{CV})$ assay (biomass quantification), filter flow rate, and MTT assay (cell viability), respectively. As the biofilm started forming, protein concentration, cell biomass, and cell viability increased while flow rate decreased (due to biomass formation, which promoted clogging).

Protein concentration for Filters FC, FA, and FB increased from 0.118 to $0.387 \mu \mathrm{g} / \mathrm{mL}, 0.132$ to $0.712 \mu \mathrm{g} / \mathrm{mL}$, and 0.126 to $0.832 \mu \mathrm{g} / \mathrm{mL}$, respectively, while the highest absorbance value at Day 9 of the MTT assay for FA and FB was recorded at 2.5-fold and 2.1-fold more than that for FC (0.534). The CV assay showed the same trend, where the highest absorbance value for FA and FB was found to be almost twofold that for FC.

Initial flow rate for all three filters was similar $(0.52 \mathrm{~m} / \mathrm{h})$ and decreased as time progressed. The flow rate was determined by maintaining an influent head of $7.5 \mathrm{~cm}$, measured from the top of the sand and collecting at least a volume of $40 \mathrm{~mL}$ with the recorded time. A larger decrease in flow rate for FA, FB, and FC compared with that before bacterial cell inoculation was $25.8 \%$, $22.8 \%$, and $9.2 \%$, respectively. The relatively higher decrease in flow rate for FA and FB was attributed to progressive biomass and viability of bacterial cells attached to the sand adsorbents affecting the tortuosity of the fluid flow. The nearly stable output of cell biomass, viability, and protein concentration after Day 10 saw fair and stable biofilm formation in FA and FB. Considering this stability, the ozone-treated samples were passed until Day 11.

\section{Residual Ozone Concentration in the Ozone-Treated Samples and PCA Analysis}

The relationship between residual ozone concentration and volume of Indigo solution required, for both matrices, is presented in Figs. 3( $a$ and b). The volume of Indigo reagent required to quench the residual ozone was slightly higher for the tap water matrix than for the NOM + bloom matrix. However, for obvious reasons the calibration curve for the latter matrix was used for estimating residual ozone in the ozone-treated samples. Overall, quenching (for every sample tested) did not take more than $1 \mathrm{~min}$ for the sample 

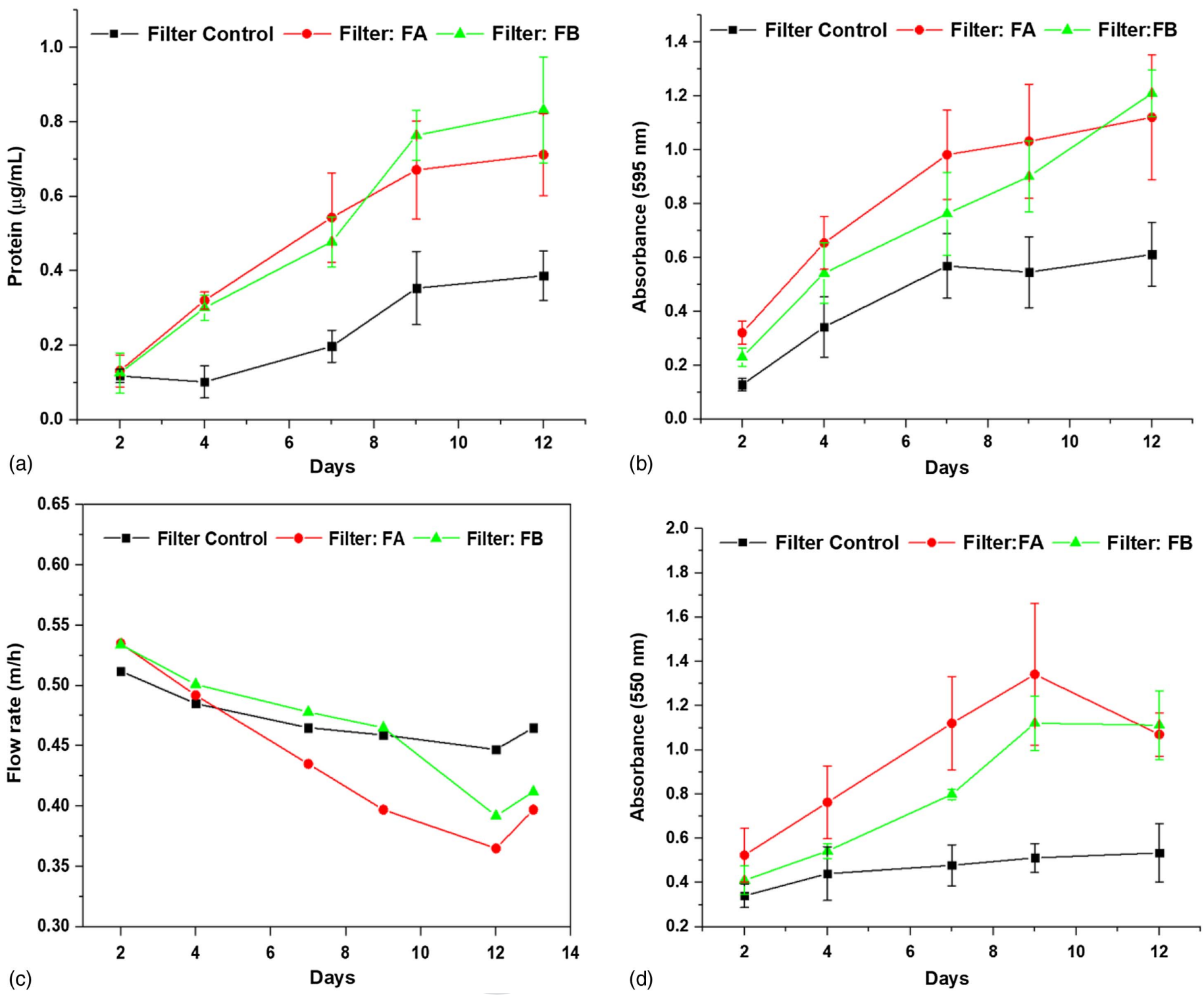

F2:1

Fig. 2. Biofilm quantification using (a) Bradford assay (protein); (b) crystal violet assay; (c) flow rate; and (d) cell viability.
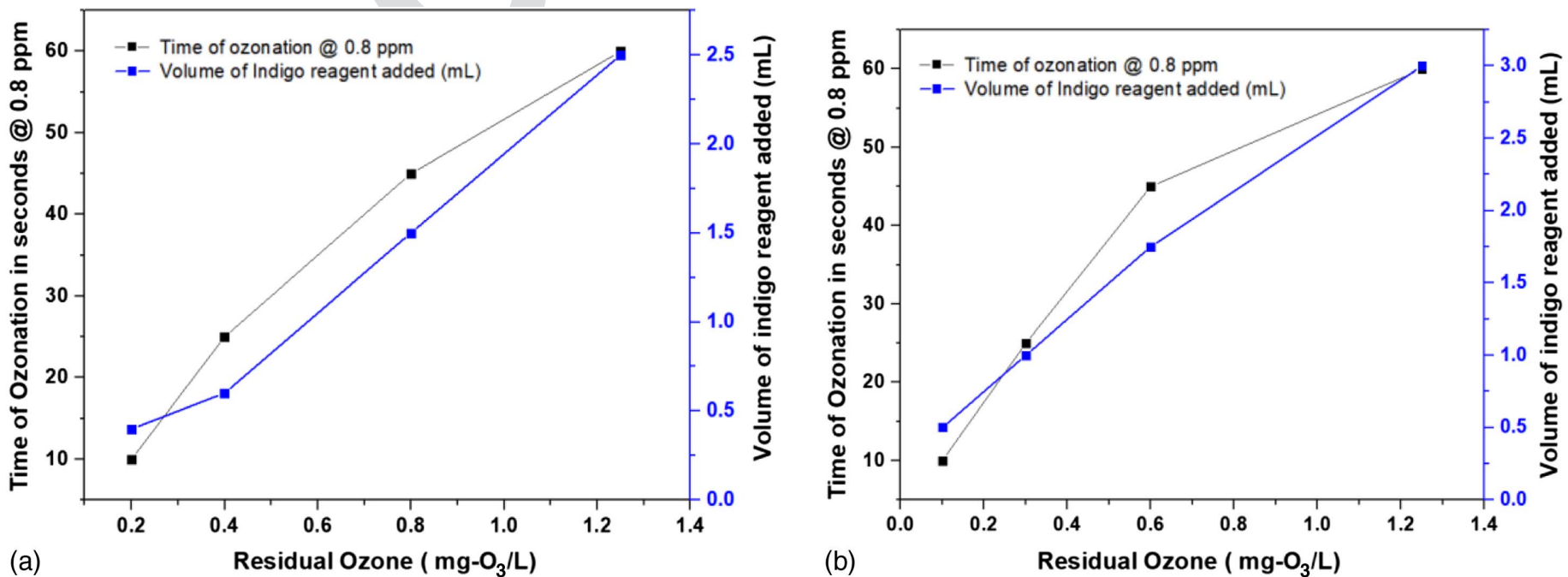

F3:1 Fig. 3. Residual ozone ( $x$-axis) and reaction time ( $y$-axis) versus volume of Indigo solution used (secondary $y$-axis) to quench residual ozone in F3:2 (a) $\mathrm{NOM}+$ bloom; and (b) tap water. 


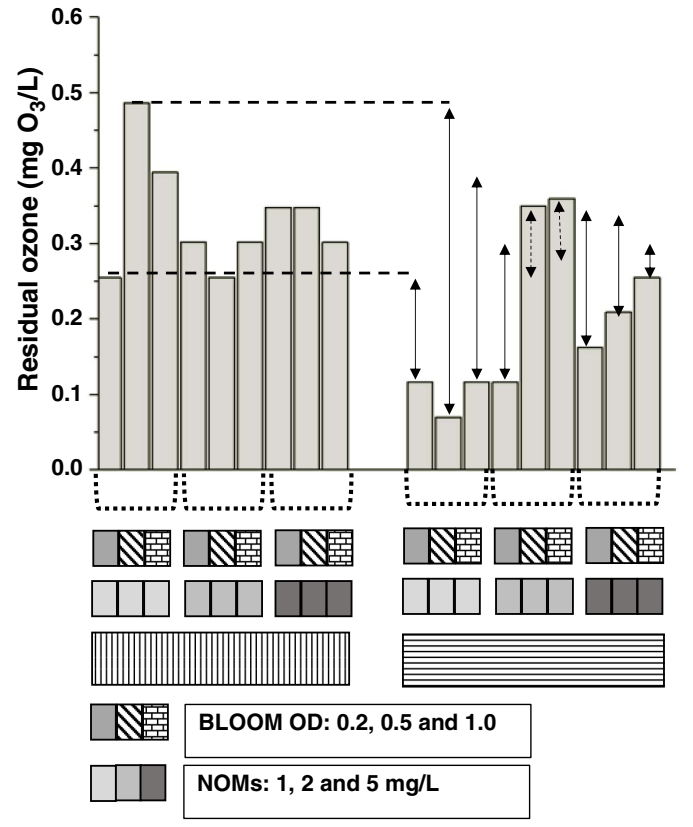

F4:1

F4:2

F4:3

F4:4

F4:5

F4:6
Fig. 4. Bar graph showing residual ozone concentration for each sample combination tested. The two-headed arrow shows the positive difference in concentration for lower $(0.8 \mathrm{mg} / \mathrm{min} / \mathrm{L})$ and higher $(1.6 \mathrm{mg} / \mathrm{min} / \mathrm{L})$ ozone doses; the dashed arrow shows the negative difference in concentration for lower $(0.8 \mathrm{mg} / \mathrm{min} / \mathrm{L})$ and higher $(1.6 \mathrm{mg} / \mathrm{min} / \mathrm{L})$ ozone doses. (longer for a higher dose and vice versa), and thus any possibility of residual ozone reacting with the NOM in the sample was inferred to be minimal.

The tap water matrix exhibited $25 \%-30 \%$ higher residual ozone for the same Indigo volume, and hence an overestimation could have been observed had the medium bloom + medium NOM matrix been chosen. Fig. 4 represents a bar chart of the residual ozone for each different samples tested post ozone treatment.

For all three filters, there existed a negative correlation between the residual ozone and MC-LR removal due to ozonation. Correlation factors of $-0.987,-0.973$, and -0.977 were found for FC, FA, and FB, respectively. This was determined by PCA [more detail is provided in Figs. S1(a-c)], where the eigenvector of the variables MC-LR_ozone and Res-Ozone was on the diametrically opposite side of the biplot axis (at a near $180^{\circ}$ angle). This signifies that the higher the residual ozone (obtained after ozonation), the lower the participation/interaction of the ozone with the MC-LR during ozonation. This trend can be attributed to the ozone molecules utilized in the oxidation of the MC-LR and the residual ozone, which eventually became a direct marker for the undegraded MC-LR in the sample solution. Except for Samples $\mathrm{N} 2 \mathrm{~B} 2 \mathrm{C} 2$ and $\mathrm{N} 2 \mathrm{~B} 3 \mathrm{C} 2$, all samples showed this phenomenon (represented by the dashed arrow in Fig. 4). Also, the combination that showed the most and least increase in MC-LR removal with an increase in ozone dose, was in Samples N1B2C2 (+67\%) and N3B3C2 (+16\%), respectively. This abnormal behavior can be explained by the fact that, under higher bloom (B3: $\mathrm{OD}_{700}$ of 1.0) and NOM (N3: $5 \mathrm{mg} / \mathrm{L}$ ), the ozone degrades the NOM and cyanobacterial biomass before oxidizing the MC-LR compound. Hence, the residual ozone is left unreacted with the MC-LR within a given contact time and shows a lower removal effect (following the negative correlation).

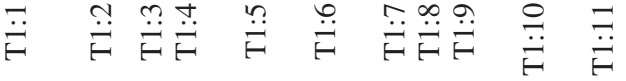

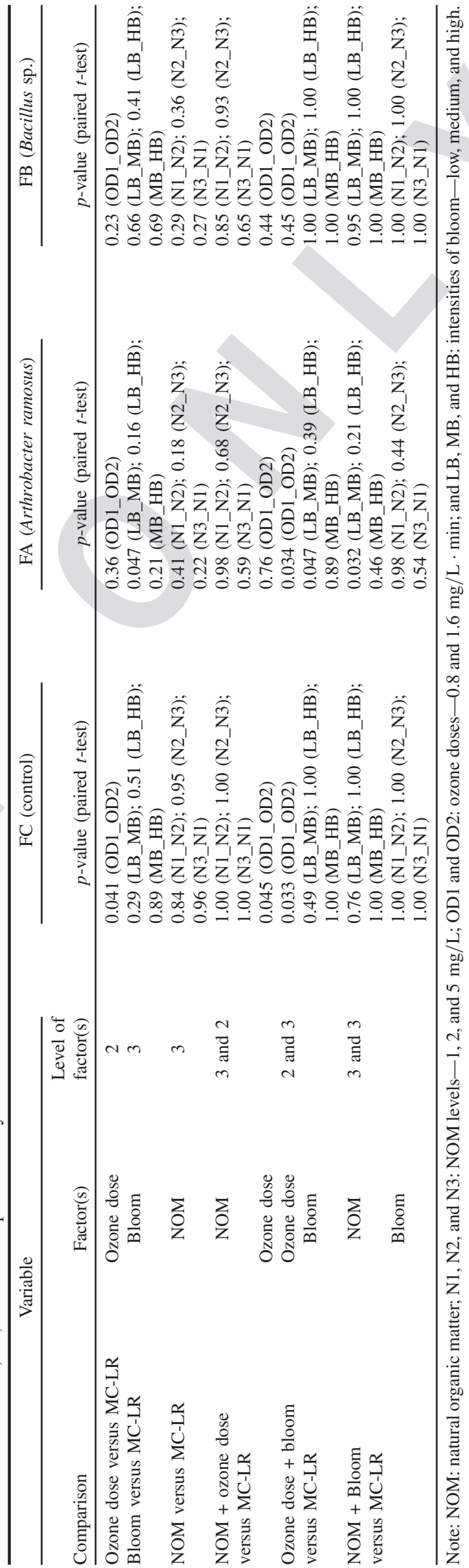


MC-LR Removal

\section{Ozonation}

In general, the residual ozone concentration for the $\mathrm{C} 2$ sample was found to be lower than for the $\mathrm{C} 1$ samples. However, N2B2C2 and
N2B3C2 (both $\mathrm{C} 2 \mathrm{~s}$ ) exhibited more the residual ozone than their C1 counterparts (as shown by the dashed arrow in Fig. 4). Hence, it can generally be inferred that the MC-LR removal for low ozone concentration $(\mathrm{C} 1 \mathrm{~s})$ is lower compared with that for high ozone concentration $(\mathrm{C} 2 \mathrm{~s})$. This may be due to less reaction of the

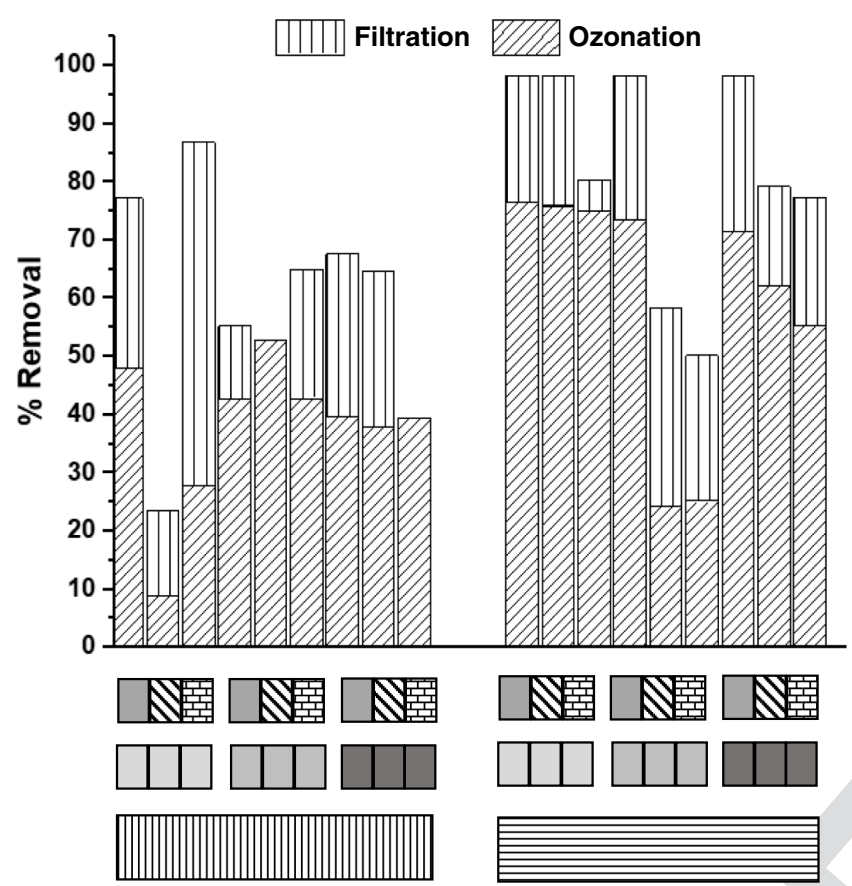

(a)

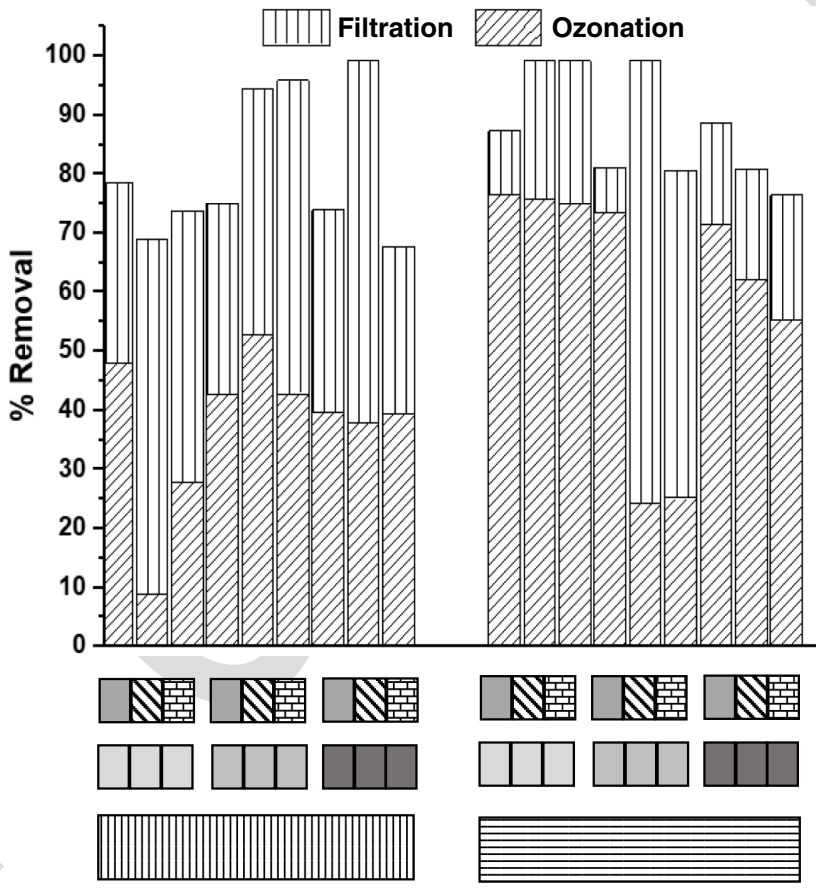

(b)

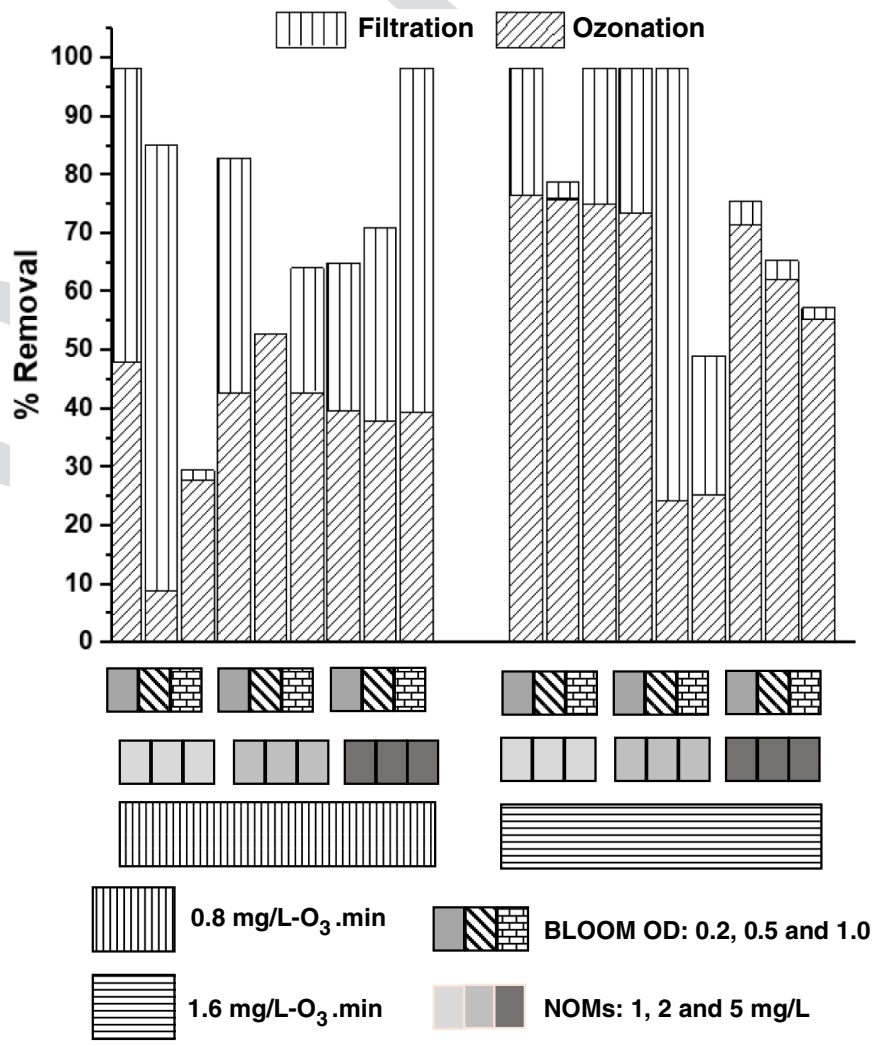

(c)

F5:1 Fig. 5. Bar graph showing the percentage removal of MC-LR for the 18 combination samples: (a) FC; (b) FA; and (c) FB. The left angled hashed bar represents MC-LR removal by ozonation; the straight hashed bar, removal by filtration. 
ozone with the MC-LR for the two exceptional combinations, which might have resulted in less MC-LR degradation compared with their counterparts with lower input ozone concentration (C1s: N2B2C1 and $\mathrm{N} 2 \mathrm{~B} 3 \mathrm{C} 1$ ). The rest of the samples followed a general trend of greater MC-LR removal with higher ozone concentration.

The relationship between ozone dose $(\mathrm{C} 1$ and $\mathrm{C} 2)$, bloom (B1, $\mathrm{B} 2$, and B3), and NOM (N1, N2, and N3) and MC-LR removal was determined statistically and is presented in Table 1 . The paired $t$-test and $p$-value showed a significant difference between ozone dose and MC-LR for FC ( $p$-value: 0.041) while FA and FB showed no significant difference ( $p$-value: 0.36 and 0.23 , respectively) because of the pivot significance of the biodegradation in MC-LR removal. On the other hand, only FA showed a significant difference between bloom (B1 and B2) and MC-LR removal, possibly because of more $M$. aeruginosa cells in the sample, which may have been responsible for hindering MC-LR removal by decreasing the activity of Arthrobacter ramosus. The same possibility holds between B1 and B3 (Table 1), but there did not exist any significant difference between these bloom levels. FA and FB showed comparatively lower $p$-values: $0.41,0.18,0.22$, and $0.29,0.36,0.27$ for N1_N2, N2_N3, and N3_N1, respectively, compared with FC ( $p$-value: $>0.8$ for all three cases). This suggests that MC-LR removal lessened in the presence of NOM in the biofilters compared with the nonbioaugmented filter (FC). This can be attributed to the scavenging between the NOMs and the oxidants formed during the oxidation reaction (Kumar et al. 2018a), which has been reported to decrease the reaction rate by $>50 \%$ (Verma and Sillanpää 2015). The effect of bloom level/NOM or NOM/ozone or ozone/bloom level on MC-LR removal as shown by two-way ANOVA is also presented in Table 1. The two variables mainly affected FA as shown by the low $p$-values in the table.

\section{Biodegradation}

Bioaugmentation of sand filters with A. ramosus (FA) and Bacillus sp. (FB) enhanced MC-LR removal. Figs. 5(a-c) are bar charts representing MC-LR removal percentage for each combination of samples for FC, FA, and FB, respectively. A total of 14 out of 18 combinations for each of Filters FA and FB showed an improvement in MC-LR degradation compared with the results for Filter FC [Figs. 5(a and b)]. Since most of the MC-LR removal occurred during the higher ozone concentration of $59.9 \% \pm 19.9 \%$ (C2s) compared with the lower concentration of $38 \% \pm 12 \%(\mathrm{C} 1 \mathrm{~s})$, biodegradation was mostly visible in the $\mathrm{C} 1$ samples.

On average, bioaugmentation of $A$. ramosus (FA) and Bacillus sp. (FB) enhanced filter performance (compared with FC) by $19.5 \%$ and $10.5 \%$ for $\mathrm{C} 1 \mathrm{~s}$ and $6 \%$ and $2 \%$ for $\mathrm{C} 2 \mathrm{~s}$, respectively. This would seem to be obvious, as a higher initial ozone concentration means a higher residual concentration in treated samples which eventually becomes part of the influent to the biofilters and so affects the physiological condition of the bacteria and their viability. Hence, MC-LR removal was relatively lower for $\mathrm{C} 2 \mathrm{~s}$ (more residual ozone-affected biocells) than for $\mathrm{C} 1 \mathrm{~s}$ (lower applied ozone concentration.

\section{Ozone-Treated Sample Toxicity Assessment Using Known MC-LR Degraders and a DWTP Native Bacterial Community}

Fig. 6 shows the standard activity curve for the PP enzyme (reported in percentage) versus an increase in MC-LR concentration. For comparison, PP percentage activity was tested in the treated samples from biofilters inoculated (co-cultured) with native bacteria (Chryseobacterium sp. and Pseudomonas fragi) obtained from the Chemin Ste-Foy DWTP filtration unit (Kumar et al. 2018b) together with the known MC-LR-degraders, A. ramosus and Bacillus sp.
A PP percentage activity of $15 \%$ was observed via PPIA for the influent (ozone-treated sample, dose: $0.8 \mathrm{mg} \times \mathrm{min} / \mathrm{L}, \mathrm{NOM}$ : $2 \mathrm{mg} / \mathrm{L}$, Bloom OD: 0.5) while $17 \%$ was observed for the effluent obtained from FC (initial MC-LR: $50 \mu \mathrm{g} / \mathrm{L}$ ). This result points to an important finding: although MC-LR concentration decreased by $30 \%-50 \%$ with sand as the adsorbing medium, the change in PP activity was observed to be just $2 \%$. This could be attributed to the other toxic by-products present in the filtered effluent generated after ozone treatment or transformed after filtration. However, the percentage PP activity increased to $33 \%$ and $47 \%$ for FB and FA, respectively. This could be attributed to a decrease in MC-LR concentration and thus reduced toxicity due to persistent ozonation-generated byproducts or postfiltration biotransformed products. As mentioned earlier, enhanced MC-LR removal was observed in the bioaugmented sand filters (at the $\mathrm{C} 1$ ozone dose) as $10.5 \%$ for FB and $19.5 \%$ for FA. Also, FA and FB showed $16 \%$ and $30 \%$ higher PP activity at the same ozone dose $(\mathrm{C} 1)$, which may suggest that the biotransformed products (parent by-products generated by ozonation) decreased proportionally and remained independent of the MC-LR-degrader applied. Nevertheless, the results showed evidence of fewer toxic compounds in the filtered water obtained from FA and FB than from FC. A detailed mass spectra analysis might provide more clarity on the nature of by-products transformed by biodegradation.

In comparison with the results obtained for individual bacteria (as discussed earlier), the inoculation of the native bacteria ( $\mathrm{X}$ in Fig. 6) alone increased PP activity to $63 \%$. Co-culturing $X$ with A. ramosus and Bacillus sp. further increased $\mathrm{PP}$ activity by $2 \%-5 \%$, to $65 \%$ and $68 \%$, respectively. Though the change in PP activity was not significant, the prospects of exploring co-culturing and native bacterial communities for MC-LR removal and related by-product toxicity are encouraging. Also, bacterial populations in bioaugmented sand filters can change with long-term water treatment. Thus, future investigation of microbial communities is essential to ascertain the feasibility of techno-economic evaluation of sand filters in water treatment.

Fig. 6. Curve showing percentage PP1A activity versus MC-LR concentration; (inset bar graph) percentage PP1A activity for various bioaugmented cases. The bar graph shows bioaugmentation in a sand filter using Arthrobacter ramosus(A), Bacillus sp. (B), Pseudomonas fragi and Chryseobacterium sp. ( X), combinations ( $+\mathrm{X}$ and $\mathrm{B}+\mathrm{X})$, and no inoculation.

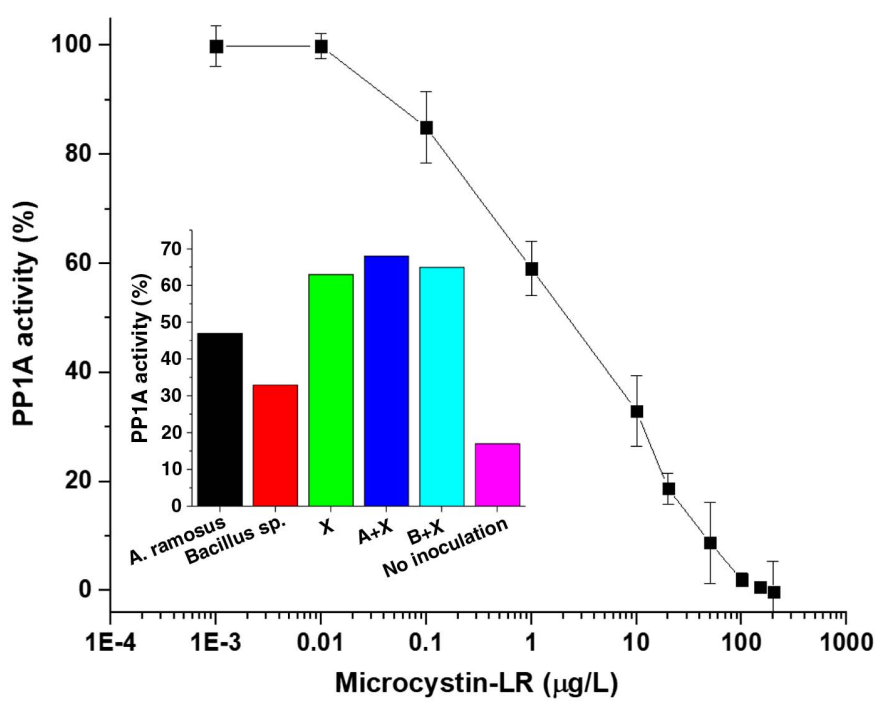




\section{Conclusion}

Hybrid ozone-biofilter treatment of a model emerging contaminant, MC-LR, was evaluated using CTs of 0.8 and $1.6 \mathrm{mg} \times \mathrm{min} / \mathrm{L}$. At these CTs, NOM at 1,2 , and $5 \mathrm{mg} / \mathrm{L}$ and cyanobacterial bloom at low, medium, and high levels were tested. Two MC-LR degraders, $A$. ramosus (Filter FA) and Bacillus sp. (Filter FB), were shown to perform differently in removing MC-LR in samples treated with ozone. A strong negative correlation (less than -0.97) was observed for all three filters (including FC) for residual ozone concentration and MC-LR removal due to ozonation. Arthrobacter ramous showed more resilience toward residual ozone (0.1-0.4 mg/L) than Bacillus sp. Statistical analysis suggested a strong influence of bloom level and NOM presence on MC-LR removal in FA and FB. The two biofilters performed better than the sand-only filter (no inoculation): FA and FB MC-LR removal efficiency improved for CT by $19.5 \%$ and $10.5 \%$ at $0.8 \mathrm{mg} \times \mathrm{min} / \mathrm{L}$ and by $6 \%$ and $2 \%$ at $1.6 \mathrm{mg} \times \mathrm{min} / \mathrm{L}$, respectively. A PPIA showed evidence of lowertoxicity by-product formation when native bacteria were co-cultured and inoculated with the known MC-LR degraders in a sand filter.

\section{Data Availability Statement}

Some or all data, models, or code that support the findings of this study are available from the corresponding author upon reasonable request (All data, models, and/or code are available).

\section{Acknowledgments}

The authors are sincerely thankful to the Natural Sciences and Engineering Research Council (Discovery Grant No. 23451). A Special thanks to Chemin Ste-Foy DWTP operator Mr. Guy Desgroseilliers, Ville de Quebec, for providing quartz sand from the plant's filtration unit. The authors are also thankful to Dr. Jerome Compte for providing the M. Aeruginosa culture, and to Mr. Dave Gilbert, president and CEO of EMO3 for providing the ozone generator.

\section{Supplemental Materials}

Fig. S1 and a description of the significance of the PCA are available online in the ASCE Library (www.ascelibrary.org).

\section{References}

Bader, H., and J. Hoigné. 1981. "Determination of ozone in water by the indigo method." Water Res. 15 (4): 449-456. https://doi.org/10.1016 /0043-1354(81)90054-3.

Bradford, M. M. 1976. "A rapid and sensitive method for the quantitation of microgram quantities of protein utilizing the principle of protein-dye binding." Anal. Biochem. 72 (1-2): 248-254. https://doi.org/10.1016 10003-2697(76)90527-3.

Brown, L. L. 2016. Human health risks from tap water chlorine disinfection byproducts: An Ohio study. Hors Research Project 283. Akron, $\mathrm{OH}$ : Honors Research Project, Univ. of Akron.

Cui, Y., Q. Wu, S. Xiao, X. An, J. Sun, and F. Cui. 2014. "Optimum ozone dosage of preozonation and characteristic change of refractory organics in landfill leachate." Ozone: Sci. Eng. 36 (5): 427-434. https://doi.org /10.1080/01919512.2013.874276.

De Vera, G. A., D. Stalter, W. Gernjak, H. S. Weinberg, J. Keller, and M. J. Farré. 2015. "Towards reducing DBP formation potential of drinking water by favouring direct ozone over hydroxyl radical reactions during ozonation.” Water Res. 87 (Dec): 49-58. https://doi.org/10.1016/j.watres 2015.09.007.

Fayad, P. B., A. Roy-Lachapelle, S. V. Duy, M. Prévost, and S. Sauvé 2015. "On-line solid-phase extraction coupled to liquid chromatography tandem mass spectrometry for the analysis of cyanotoxins in algal blooms." Toxicon 108 (Dec): 167-175. https://doi.org/10.1016/j.toxicon 2015.10.010

Gardoni, D., A. Vailati, and R. Canziani. 2012. "Decay of ozone in water: A review." Ozone: Sci. Eng. 34 (4): 233-242. https://doi.org/10.1080 /01919512.2012.686354.

Gerrity, D., M. Arnold, E. Dickenson, D. Moser, J. D. Sackett, and E. C. Wert. 2018. "Microbial community characterization of ozone-biofiltration systems in drinking water and potable reuse applications." Water Res. 135 (May): 207-219. https://doi.org/10.1016/j.watres.2018.02.023.

Goel, S., R. M. Hozalski, and E. J. Bouwer. 1995. "Biodegradation of NOM: Effect of NOM source and ozone dose." J. Am. Water Works Assoc. 87 (1): 90-105. https://doi.org/10.1002/j.1551-8833.1995.tb06304.x.

Hallé, C., P. M. Huck, and S. Peldszus. 2015. "Emerging contaminant removal by biofiltration: Temperature, concentration, and EBCT impacts." J. Am. Water Works Assoc. 107 (7): E364-E379. https://doi.org/10.5942 /jawwa.2015.107.0086

Khong, N. M. H., Y. S. Khaw, M. F. Nazarudin, and F. M. Yusoff. 2019. "Microcystis aeruginosa grown in different defined media leads to different cultivable heterotrophic bacteria composition that could influence cyanobacterial morphological characteristics and growth properties." Preprint. https://doi.org/10.1101/721175.

Kumar, P., K. Hegde, S. K. Brar, M. Cledon, and A. Kermanshahi Pour. 2018a. "Physico-chemical treatment for the degradation of cyanotoxins with emphasis on drinking water treatment-How far have we come?" J. Environ. Chem. Eng. 6 (4): 5369-5388. https://doi.org/10.1016/j.jece 2018.08.032

Kumar, P., K. Hegde, S. K. Brar, M. Cledon, A. Kermanshahi-Pour, A. Roy-Lachapelle, and R. Galvez-Cloutier. 2018b. "Biodegradation of microcystin-LR using acclimatized bacteria isolated from different units of the drinking water treatment plant." Environ. Pollut. 242 (Part A): 407-416. https://doi.org/10.1016/j.envpol.2018.07.008.

Kumar, P., H. D. P. Rubio, K. Hegde, S. K. Brar, M. Cledon, A. Kermanshahi-Pour, S. Sauvé, A. Roy-Lachapelle, and R. GalvezCloutier. 2019. "Agro-industrial residues as a unique support in a sand filter to enhance the bioactivity to remove microcystin-Leucine arginine and organics." Sci. Total Environ. 670 (Jun): 971-981. https://doi.org /10.1016/j.scitotenv.2019.03.260.

Li, X.-F., and W. A. Mitch. 2018. "Drinking water disinfection byproducts (DBPS) and human health effects: Multidisciplinary challenges and opportunities." Environ. Sci. Technol. 52 (4): 1681-1689. https://doi.org /10.1021/acs.est.7b05440.

Petrovic, M. 2003. "Analysis and removal of emerging contaminants in wastewater and drinking water." TrAC Trends Anal. Chem. 22 (10): 685-696. https://doi.org/10.1016/S0165-9936(03)01105-1.

Petrovic, M., E. Eljarrat, M. J. Lopez de Alda, and D. Barcelo. 2004. "Endocrine disrupting compounds and other emerging contaminants in the environment: A survey on new monitoring strategies and occurrence data." Anal. Bioanal. Chem. 378 (3): 549-562. https://doi.org/10 .1007/s00216-003-2184-7.

Schlüter-Vorberg, L., C. Prasse, T. A. Ternes, H. Mückter, and A. Coors. 2015. "Toxification by transformation in conventional and advanced wastewater treatment: The antiviral drug acyclovir." Environ. Sci. Technol. Lett. 2 (12): 342-346. https://doi.org/10.1021/acs.estlett.5b00291.

Verma, S., and M. Sillanpää. 2015. "Degradation of anatoxin-a by UV-C LED and UV-C LED/ $\mathrm{H}_{2} \mathrm{O}_{2}$ advanced oxidation processes." Chem. Eng. J. 274 (Aug): 274-281. https://doi.org/10.1016/j.cej.2015.03.128.

von Gunten, U. 2018. "Oxidation processes in water treatment: Are we on track?" Environ. Sci. Technol. 52 (9): 5062-5075. https://doi.org/10 .1021/acs.est.8b00586.

Zoumpouli, G. A., M. Scheurer, H.-J. Brauch, B. Kasprzyk-Hordern, J. Wenk, and O. Happel. 2019. "COMBI, continuous ozonation merged with biofiltration to study oxidative and microbial transformation of trace organic contaminants." Environ. Sci. Water Res. Technol. 5 (3): 552-563. https://doi.org/10.1039/c8ew00855h. 


\section{Queries}

1. Please check and confirm that all the corrections are incorporated cor $\overline{\bar{p}} \mid \mathrm{y}$.

2. ASCE style for fences in math is in the order $\{[0]\}$. Please check to ensure that iٓ nath conforms to this ASCE style.

3. Please prov submitted date and link for Ref. Khong et al. (2019).
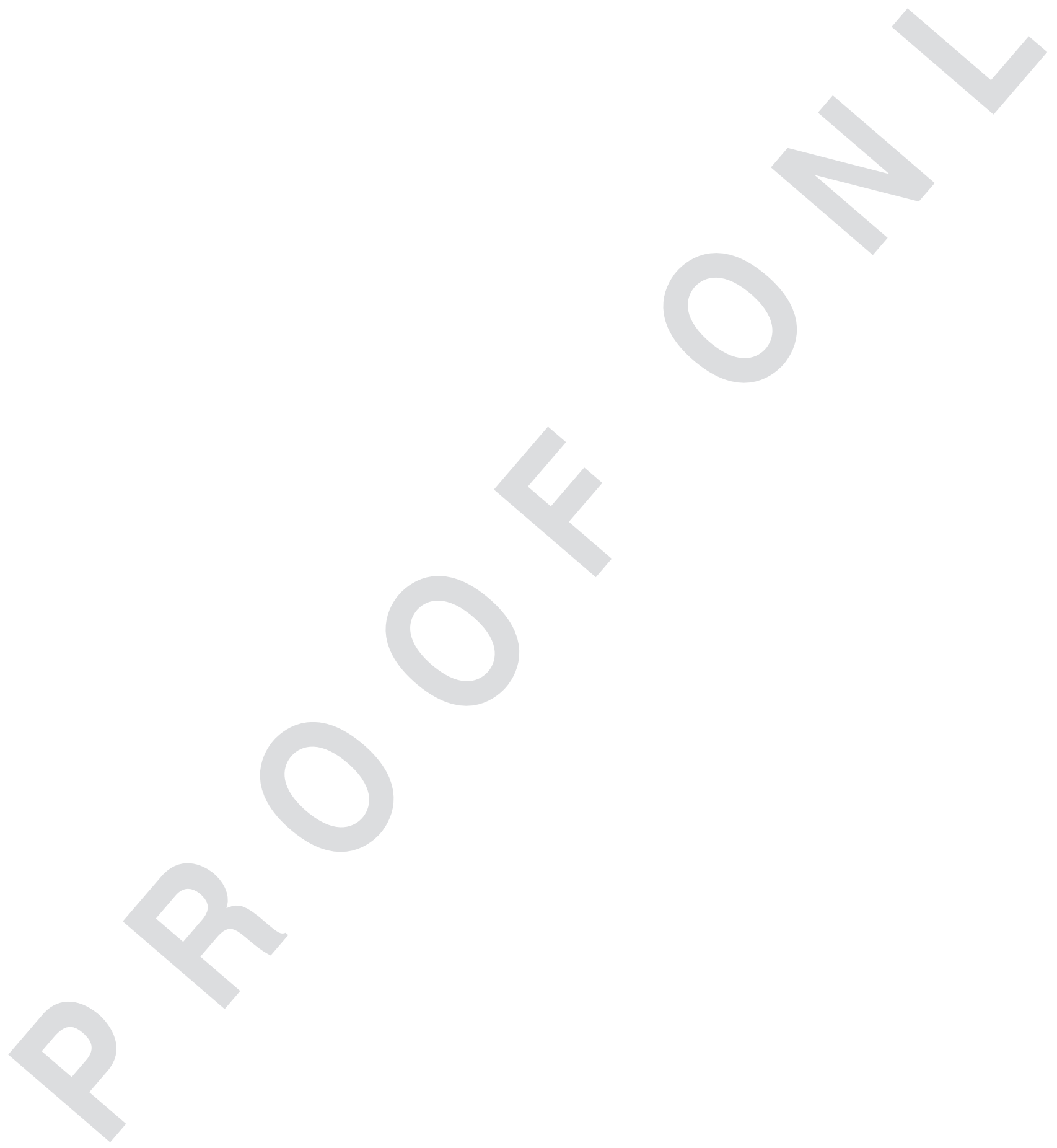